ORIGINAL ARTICLE

\title{
Anti-Obesity Effect Of Mushroom (Ganoderma Lucidum) On Experimentally Induced Obese Rats
}

\author{
*Rukhsana Amin'1, Md. Zakirul Islam², Moushumi Sen³, \\ Sohely Nazneen Eva ${ }^{4}$, Suha Jesmin ${ }^{5}$, Shamsun Nahar ${ }^{6}$ \\ ${ }^{1}$ Dr. Rukhsana Amin, Dept. of Pharmacology and Therapeutics \\ Anwer Khan Modern Medical College, Dhaka. \\ ${ }^{2} \mathrm{Dr}$. Md. Zakirul Islam, Department of Pharmacology \& \\ Therapeutics, Eastern Medical College \& Hospital, Comilla \\ ${ }^{3}$ Dr. Moushumi Sen, Dept. of Biochemistry, Anwer Khan Modern Medical College, Dhaka. \\ ${ }^{4}$ Dr. Sohely Nazneen Eva, Department of Biochemistry, BIRDEM, Dhaka. \\ ${ }^{5}$ Dr. Suhan Jesmin, Dept. of OBS \& Gynae, Anwer Khan Modern Medical College, Dhaka. \\ ${ }^{6}$ Dr. Shamsun Nahar, Dept. of Pharmacology and Therapeutics, \\ Anwer Khan Modern Medical College, Dhaka \\ * Corresponding author
}

\begin{abstract}
This experimental study was done to determine whether Ganoderma Lucidum (GL), a renowned medicinal species, has an effect on body weight in an obese animal model induced by the administration of a fatty mixture diet. The study was carried out in the department of Pharmacy, Jahangirnagar University and National Mushroom Development and Extension Center (NAMDEC) with 36 rats were divided into 3 groups as follows. The Control group (C) received normal/basal laboratory diet, experimental group (E) was fed fatty mixture diet and mushroom fed group (M) received 5\% powder of GL with fatty mixture for 28 days. 5\% powder of GL administration significantly reduced body weight in obese rats than group E. The present study suggests that GL may serve as a new potential natural product for the prevention of obesity.
\end{abstract}

ABSTRACT

Key Words: Ganoderma Lucidum (GL), Obesity

\section{Introduction}

At the present time, obesity is an important health problem. Half or more of the adult population is now identified as overweight (body mass index or $\left.\mathrm{BMI}>25 \mathrm{~kg} / \mathrm{m}^{2}-30 \mathrm{~kg} / \mathrm{m}^{2}\right)$ or obese $(\mathrm{BMI} \geq 30$ $\left.\mathrm{kg} / \mathrm{m}^{2}\right)$ in no less than 11 member countries of the Organization for Economic Cooperation and Development $(\mathrm{OECD})^{1}$. Obesity is one of the significant risk factors for metabolic syndrome, which include hypertension and hyperlipidaemia, potentially leading to type - 2 diabetes, cardiovascular disease, and nonalcoholic fatty liver disease ${ }^{2,3}$. Recently, it was reported that several food components have an anti hyperlipidaemia effect in vivo. For example, isohumulones ${ }^{4}$, bitter acids derived from hops and sesame, a sesame lignan ${ }^{5}$, improve lipid

AKMMC J 2012: 3(2): 11-14 metabolism in rodents. Also, several types of mushroom - Pleurotus Ostreatus $^{6}$, Grifola Frondosa (maitake) $)^{7}$, Flammulina Velutips ${ }^{7}$, Lentinus Edodes (shitake) ${ }^{8}$, Ganoderma Lucidum ${ }^{9}$ showed lowering effect of cholesterol synthesis or cholesterol absorption or by enhancement of fecal cholesterol excretion.

Mushroom is one unique food abundant in essential macro and micronutrients, highest in dietary fiber and water, less calorie producing, low carbohydrate content and good sources of protein and fat. Ganoderma Lucidum, known as the "Mushroom of immortality" in Japan has been used for a wide range of health benefits. A number of laboratory studies have shown anti neoplastic effect of fungal extracts or isolated compounds against some types of Cancer ${ }^{10}$. It has also been found to inhibit platelet aggregation and 
to lower blood pressure, cholesterol and blood sugar $^{11}$. But little is known about the anti obesity efficacy of GL mushroom. Thus, the present study was conducted to feed $5 \%$ powder of GL in experimentally induced obese rat to determine its anti - obesity effect.

\section{Materials and Methods}

36 Long Evans rats, weighing between 120 - 140 gms were used as testing animals for 28 days. They were kept in cages in an animal house at 23 $\pm 2^{\circ} \mathrm{C}$ under 12 hour light - dark cycles. They had free access to fresh diet and drinking water during the experimental period. Rats were divided in 3 groups. Each group was composed of 12 rats: i) Rats that were fed a basal diet (Group C), ii) Rats that were fed an additional Fatty mixture diet (Group E) and iii) Rats that were fed Fatty mixture diet $+5 \%$ powder of GL (Group M). Mushroom (GL) were cultivated and harvested in culture laboratory of National Mushroom Development and Extension Center (NAMDEC), Savar, Dhaka. The fruiting bodies of mushroom were dried in oven and crushed into powder. The powder was mixed with the basal diet.

The composition of the basal diet for rats was as follows $(\mathrm{g} / 100 \mathrm{~g})$ :

Wheat flower - 50; rice powder - 11; casein (non fat) - 8; egg white - 10; soybean oil - 1 ; table salt - 0.5 ; vitamin mixture -0.25 and mineral mixture -0.25 . The composition of vitamin mixture in the diet was as follows (gram/100g vitamin mixture): retinyl acetate - 9.5 X 10-4; cholecalciferol - 1.2 $\mathrm{X} 10-3$; ? - tochoferol acetate - 0.05 ; thiamin hydrochloride -2.4 ; nicotinic acid - 12 ; riboflavin - 2.4; D - calcium pantothenate - 9.6; pyridoxine hydrochloride - 1.2; folic acid - 9.5 X 10-2; vitamin $\mathrm{K}-0.25$; cyanocobalamine - 9.5 X 10-3; inositol - 47.95 and ascorbic acid - 24.0. The composition of mineral mixture added to diet was as follows $(\mathrm{g} / 100 \mathrm{~g}$ of mineral): calcium gluconate - 28.5; K2HPO4 - 17.3; $\mathrm{CaCO} 3$ - 26.0; MgSO4 12.6; KCL -12.6; CuSO4 - 0.06; FeSO4 - 0.3; MnSO4 - 0.55; NaF - 2.5 X 10-4 ; KI - 9 X 10-4; sodium molybdate - 3 X 10-4; $\mathrm{SeO} 2$ - 3 X 10-4; $\mathrm{CrSO} 2$ - 1.5 X 10-3.

\section{Fatty Mixture}

Cholesterol and cholic acid were obtained from the market in powdered form which was manufacture by "LOBA Chemic". A mixture of $1 \%$ cholesterol, $0.25 \%$ cholic acid and standard laboratory diet was administered on rats as fatty mixture diet for 28 days.

Statistical Analysis

Results were expressed as the mean \pm S.E. A one - way analysis of variance (ANOVA) was used for the data analysis, using SPSS (Statistical Package for Social Sciences) 18.0 software. ANOVA using Bonferroni test at $p$ values less than 0.05 was considered as significant.

\section{Results}

Effect of fatty mixture diet on body weight of rats:

Feeding a fatty mixture diet for 28 days on group E produced significant $(\mathrm{P}<0.05)$ increase in body weight in comparison to group $\mathrm{C}$ (Shown in Table 1 \& Figure 1).

Effect of 5\% powder of Ganoderma Lucidum on experimentally induced obese rats $(\mathrm{M} \mathrm{E})$ :

After 28 days of treatment, body weight of group $\mathrm{M}$ significantly $(\mathrm{P}<0.05)$ decreased in comparison with that of group $\mathrm{E}$ (Shown in Table $1 \&$ Figure 1).

Table 1: Effect of Ganoderma Lucidum on Body Weight Gain in Different Rat Groups

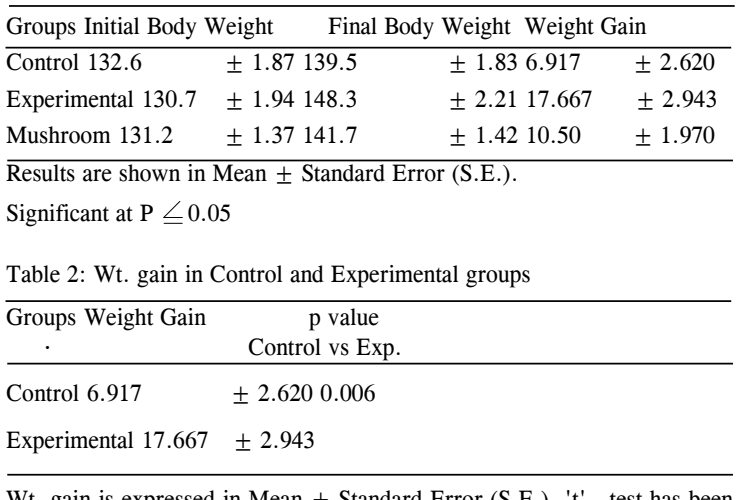

Wt. gain is expressed in Mean \pm Standard Error (S.E.). ' $t$ ' - test has been done. Significant at $\mathrm{P} \leqslant 0.05$ 
Table 3: Wt. gain in Experimental and Mushroom groups

\begin{tabular}{ll}
\hline Groups Weight Gain & $\begin{array}{c}\mathrm{p} \text { value } \\
\text { Experimental vs Mushroom }\end{array}$ \\
\hline Experimental 17.667 & \pm 2.943 \\
& 0.019 \\
Mushroom 10.50 & \pm 1.970
\end{tabular}

Wt. gain is expressed in Mean \pm Standard Error (S.E.). ' $t$ ' - test has been done. Significant at $\mathrm{P} \leqslant 0.05$

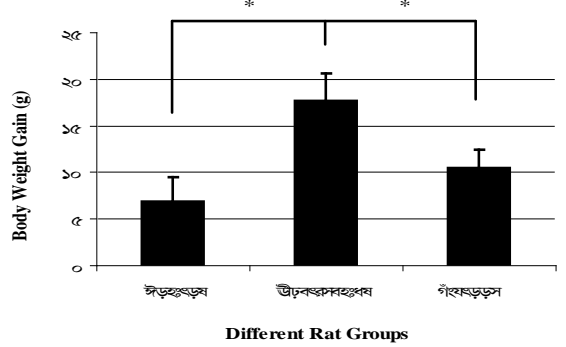

Fig.1 Effect of Ganoderma Lucidum on Body Weight Gain in Different Rat Groups Results are shown in Mean \pm Standard Error (S.E.). * = Significant at $P \leq 0.05$

\section{Discussion}

Hyperlipidaemia/ Obesity are a significant risk factor for the development of atherosclerosis, cardiovascular disease and non - alcoholic fatty liver disease ${ }^{3}$. In this study, we used rat, fed fatty mixture of diet as an animal model of obesity and hyperlipidaemia ${ }^{11}$, and evaluated the anti obesitic effects of GL.

As for the results, $5 \%$ powder of GL fed group (Group M) significantly $(\mathrm{P}<0.05)$ decreased body weight as compared to Group E. No meaningful differences in the food intakes of the two groups were detected.

In similar researches observations shows that feeding of $P$. (Plerotus) ostreatus, P. sajor-caju and $P$. florida mushroom reduced body weight significantly in hypercholesterolemic rats by $17.36 \%, 23.37 \%$ and $24.13 \%$ respectively ${ }^{12}$. Besides this, other mushroom like Yamabushitake (Hericium erinaceus) also reduce body wt. significantly in high-fat diet fed mice ${ }^{13}$. Whereas, P. tuber-regium and Termitomycetes clypeatus feeding reduced body wt. in hypercholesterolemic rats slightly but not significantly 14 .

Known as reishi or mannentake to the Japanese and Ling Zhi to the Chinese, GL is renowned for its medicinal properties. Reishi often is associated with health and recuperation, longevity, wisdom and happiness. It is believed that certain triterpenes and polysaccharides may account for the multiple activities of Reishi. Thus, considerable time and effort has gone into the isolation and characterization of these compounds.

Ganoderma lucidum contain approximately 400 different bioactive components, which mainly include triterpenoids, polysaccharides, nucleotides, sterols, steroids, fatty acids, amino acids, soluble proteins, oleic acid, anergosterol peroxide and inorganic ions $(\mathrm{Mg}, \mathrm{Ca}, \mathrm{Zn}, \mathrm{Mn}$, $\mathrm{Fe}, \mathrm{Cu}, \mathrm{Ge}$ etc). Two new lanostane triterpenes, methyl lucidenate $\mathrm{N}$ and $\mathrm{t}$ - butyl lucidinate $\mathrm{B}$, reduced TG accumulation significantly ${ }^{15}$.

Some research indicates that the GL mushroom, an ancient remedy known to some health practitioners, can aid weight loss.

Scant studies exist that conclusively prove the efficacy of GL as a weight loss tool or as a means to travel obesity. One study published in the "Journal of Microbiology", in 2004 found that a compound extracted from Ganoderma reduced glucose levels in test animals and suggested that GL might be effective in the oral treatment of diabetes and obesity ${ }^{16}$.

Dr. Taro Tamura of Kinki University, reported "Since GL can eliminates obesity, overweight people do not need to worry about their obese figures and the figure conscious women do not need to suffer the pain and ill effects of starvation diets and weight loss drugs".

\section{Conclusion}

The present study suggests that GL may serve as a new potential natural product for the prevention of obesity.

\section{Acknowledgement}

This study was supported by Strengthening Mushroom Development Project, National Mushroom Development and Extension Center (NAMDEC), Savar, Dhaka and Department of Pharmacy, Jahangirnagar University. 
References

1.OECD, "OECD Factbook 2009: Economic, Environmental and Social Statistics". OECD Publishing, Paris 2009; pp. 250 - 251.

2. Kopelman PG. Nature 2000; 404 : 635 - 643.

3. Funahashi T and Matsuzawa Y. Ann. Med. 2007; 39 : 482 - 494.

4. Miura $\mathrm{Y}$, Hosono M, Oyamada C, Odai H, Oikawa S and Kondo K. Br. J. Nutr. 2005; 93 : 559 - 567.

5. Ashakumary L, Rouyer I, Takahashi Y, Ide T, Fukuda N, Aoyama T, Hashimoto T, Mizugaki M and Sugano M. Metabolism 1999; 48 : 1303 - 1313.

6. Hossain S, Hashimoto M and Chowdhury EK. Dietary mushroom (Pleurotus ostreatus) ameliorates atherogenic lipid in hypercholesterolemic rats. Clinical and Experimental Pharmacology and Physiology 2003; $30: 470$ - 475.

7. Fukushima M, Ohashi T, Fujiwara Y, Sonoyama K and Nakano M. Cholesterol lowering effects of Maitake fiber, Shiitake fiber and Enokitake fiber in rats. Exp Biol Med 2001; 226 (8) : 758 - 765.

8. Shimada Y, Morita T and Sugiyama K. Effects of dietary Eritadenine on ?6 - Desaturase activity and fatty acid profiles of several lipids in rats fed different fats. Biosci Biotechnol Biochem 2002; 66(7) : 1605 1609.

9. Berger A, Rein D, Krathy E, Monnard I, Hajjaj H, Meirim I, Piguet - Welsch C, Hauser J, Mace K and Niederberger P. Cholesterol lowering properties of Ganoderma Lucidum in vitro, ex - vivo and in hamsters and minipigs. Lipids in health and disease 2004; $3: 2$.
10. Gaziano JM, Herbert $\mathrm{PR}$ and Hennekens $\mathrm{CH}$. Cholesterol reduction: weighing the benefits and risks. Ann Intern Med 1996; 124 : 914 - 918.

11. Ohtsuru M. Anti-obesity activity exhibited by orally administrative powder of Maitake mushroom (Grifola frondosa). Anshin July 1992; 198.

12. Lee TS, Lee $Y$, Alam N, Khan A and Lee M. Comparative effects of oyster mushrooms on lipid profile, liver and kidney function in hypercholesterolemic rats. Mycobiology 2009; 37 (1) : 37 - 42 .

13. Shirakawa H, Hiwatashi K, Kosaka Y, Suzuki N and Hata K. Yamabushitake mushroom (Hericium erinaceus) improved lipid metabolism in mice fed a high-fat diet. Biosci.Biotechnol.Biochem 2010; 74 (7) : 1447 - 1451.

14. Oyetayo, F.L. Responses of plasma lipids to edible mushroom diets in albino rats. African Journal of Biotechnology 2006; 5 (13) : 1263 - 1266.

15. Iksoo L, Hongjin K, Ui JY, Jin PK and Byungsun M. Effect of lanostane triperpenes from the fruiting bodies of GL on Adipocyte Differentiation in 3T3 L1 cells. Planta Med 2010; 76 (14) : 1558 - 1563.

16. Kim $\mathrm{S}$ and Nho H. Isolation and characterization of Glucosidase inhibitor from the fungus Ganoderma Lucidum. Journal of Microbiology June 2004. 